\title{
Effects on the Cost and Utilization of Proton Pump Inhibitors From Adding Over-the Counter Omeprazole to Drug Benefit Coverage in a State Employee Health Plan
}

\author{
BRITTANY N. HARRIS; DONNA S. WEST, RPh, PhD; JILL JOHNSON, PharmD; \\ SONG HEE HONG, PhD; and CINDY D. STOWE, PharmD
}

\begin{abstract}
OBJECTIVE: To evaluate the financial effects in a state employee health plan of a change in the drug coverage policy to include over-the-counter (OTC) omeprazole in a tier-copayment drug benefit design that favored the OTC drug.

METHODS: The policy change in the Arkansas State Employee Benefit Division (EBD) involved 2 principal parts: OTC omeprazole placed in a new 0TC copayment tier (\$5) and an increase in pharmacy reimbursement to a $\$ 13$ dispensing fee for each OTC omeprazole prescription. The prescription claims database was used to examine utilization and cost data for beneficiaries who received prescriptions for a proton pump inhibitor (PPI) during the 2-month period (January and February 2004) preceding the change in policy to cover OTC omeprazole compared with the 2-month period following the policy change (March and April 2004).

RESULTS: During the first week of the new policy (March 1-7, 2004), 0TC omeprazole accounted for $47 \%$ of all PPI claims. From the third week through the end of the 2-month study period, OTC omeprazole represented $60 \%$ of PPI claims. This shift to OTC omeprazole from prescription PPIs produced EBD average savings of $\$ 40.86$ (40.5\%) per PPI claim in the first 2 months after implementation of coverage of OTC omeprazole compared with the immediate previous 2-month period. The average copayment savings for EBD beneficiaries were $\$ 4.20(16.5 \%)$ per PPI claim. The average increase in pharmacy reimbursement was $118 \%$ (\$6.27 per claim in the postperiod versus $\$ 2.88$ per claim in the preperiod). Despite a $17.2 \%$ increase in utilization as measured by days of PPI therapy per member per month (1.91 PMPM) in the postperiod versus 1.63 in the preperiod, EBD savings were $\$ 2.11$ (38.9\%) PMPM. Based upon PMPM savings of \$2.56 in the second month of coverage of OTC omeprazole, annual savings would be about $\$ 3,978,240$ for average eligible membership of 129,500 in this state employee health plan.
\end{abstract}

CONCLUSION: This policy change to include coverage of OTC omeprazole in the state employee drug benefit plan produced savings to the state of as much as $50 \%$ of the total cost of PPI drugs despite an apparent small increase in utilization of PPIs and an increase in pharmacy reimbursement of more than $100 \%$. Plan beneficiaries realized significant savings on average for PPI drugs and particularly for each OTC omeprazole prescription.

KEYWORDS: Proton pump inhibitors, OTC medications, Prescription copayments, Prescription utilization, Tier copayment

J Manag Care Pharm. 2004;10(5):449-55
$\mathrm{P}$ rescription drug expenditures continue to rise faster than any other expenditure in the medical service sector. ${ }^{1}$ Double digit annual increases in prescription costs have left health plans looking to decrease their costs. ${ }^{1-3}$ Health plans have utilized 3-tier formularies, higher copayments, and now are considering coverage of over-the-counter (OTC) product equivalents, where available, to reduce costs. ${ }^{4}$ Some payers are encouraging the use of OTC formulations in place of higher-cost prescription alternatives. In 2003, 32.1\% of all health maintenance organizations covered at least 1 OTC drug. ${ }^{5}$

In recent years, there has been an increase in the number of products switched from prescription-only to OTC status, increasing the potential for coverage of OTC products in prescription drug benefits. ${ }^{6}$ In 2002, the U.S. Food and Drug Administration (FDA), for the first time, approved OTC loratadine at the same strength and dosage for seasonal allergic rhinitis as was previously available only by prescription. In June 2002, the Nonprescription Drugs Advisory Committee (NDAC) and the Gastrointestinal Drugs Advisory Committee, reversed an earlier decision and voted in favor of OTC status for omeprazole (Prilosec), a proton pump inhibitor (PPI). OTC omeprazole was approved at a dose of $20 \mathrm{mg}$ daily for the prevention of symptoms of frequent heartburn. ${ }^{7}$

The availability of OTC omeprazole, which is less expensive than either brand or generic prescription (Rx) omeprazole, presents a potentially important savings opportunity because PPIs represent a huge expense with $\mathrm{Rx}$ omeprazole alone ranking second in retail sales, accounting for $\$ 4$ billion in 2001. ${ }^{1}$ As a class, antiulcer products ranked second in over-all retail sales, at $\$ 10.8$ billion in $2001 .^{1}$ The patent on

\section{Authors}

BRITTANY N. HARRIS, is a PharmD candidate; DONNA S. WEST, RPh, PhD is an assistant professor; JILL JOHNSON, PharmD, is an associate professor; SONG HEE HONG, PhD, is an assistant professor; and CINDY D. STOWE, PharmD, is an associate professor, University of Arkansas for Medical Sciences College of Pharmacy, Little Rock, Arkansas.

AUTHOR CORRESPONDENCE: Brittany N. Harris, PharmD Candidate, University of Arkansas for Medical Sciences College of Pharmacy, 4301 W. Markham St., Slot 522, Little Rock, AR 72205-7199. Tel: (501) 686-7610; Fax: (501) 296-1168; E-mail: bnharris@uams.edu

Copyright $\odot$ 2004, Academy of Managed Care Pharmacy. All rights reserved. 


\begin{tabular}{|c|c|c|}
\hline & $\begin{array}{c}\text { Prepolicy } \\
\text { (January/February 2004) }\end{array}$ & $\begin{array}{c}\text { Postpolicy } \\
\text { (March/April 2004) }\end{array}$ \\
\hline \multicolumn{3}{|l|}{ Copayment } \\
\hline $\begin{array}{l}\text { OTC omeprazole } \\
\text { Generic Rx omeprazole } \\
\text { Rx (brand) omeprazole } \\
\text { Rabeprazole } \\
\text { Esomeprazole } \\
\text { Lansoprazole } \\
\text { Pantoprazole }\end{array}$ & $\begin{array}{c}\text { Not covered by plan } \\
\$ 10 \\
\$ 25 \\
\$ 25 \\
\$ 25 \\
\$ 50 \\
\$ 50\end{array}$ & $\begin{array}{c}\$ 5 \text { (new OTC tier) } \\
10 \text { mg cap only: } \$ 25 \\
\text { Not covered } \\
\$ 50 \\
\$ 50 \\
\$ 50 \\
\$ 50\end{array}$ \\
\hline \multicolumn{3}{|l|}{ Dispensing fee } \\
\hline $\begin{array}{l}\text { OTC } \\
\mathrm{Rx}\end{array}$ & $\begin{array}{l}\text { Not covered } \\
\$ 2.50\end{array}$ & $\begin{array}{l}\$ 13 \\
\$ 2.50\end{array}$ \\
\hline \multicolumn{3}{|l|}{$\begin{array}{l}\text { Ingredient cost } \\
\text { reimbursement }\end{array}$} \\
\hline $\begin{array}{l}\text { OTC } \\
\operatorname{Rx}\end{array}$ & $\begin{array}{l}\text { Not covered } \\
\text { AWP - } 13 \%\end{array}$ & $\begin{array}{l}\text { AWP }-13 \% \\
\text { AWP }-13 \%\end{array}$ \\
\hline \multicolumn{3}{|l|}{ Days-supply limit* } \\
\hline $\begin{array}{l}\text { OTC } \\
\operatorname{Rx}\end{array}$ & $\begin{array}{l}\text { Not covered } \\
\text { 30-day supply }\end{array}$ & $\begin{array}{l}\text { 42-day supply } \\
30 \text {-day supply }\end{array}$ \\
\hline
\end{tabular}

* Days supply limit; there is not a quantity limit on any PPI.

OTC = over the counter; $R x=$ prescription; $A W P=$ average wholesale price .

Rx omeprazole expired in October 2001, but the release of a generic product was delayed due to litigation. ${ }^{8}$ A generic Rx omeprazole is now available but only as a single-source product. Therefore, it is not significantly less expensive than brand-name Rx omeprazole.

Proton pump inhibitors work by inhibiting the hydrogenpotassium adenosine triphosphatase pump, the last step leading to acid production in the stomach. Systematic reviews have compared clinical efficacy of equipotent doses of available PPIs for symptomatic relief and the maintenance of healing in gastroesophageal reflux disease (GERD), for the healing and maintenance of healing in gastric and duodenal ulcers, and in combination with antibiotic regimens for Helicobactor pylori eradication..$^{9-11}$ The data consistently support that omeprazole $20 \mathrm{mg}$ is similar in efficacy to lansoprazole (Prevacid) $30 \mathrm{mg}$, pantoprazole (Protonix) $40 \mathrm{mg}$, and rabeprazole (Aciphex) $20 \mathrm{mg}$.

While there are no published head-to-head comparisons of esomeprazole (Nexium) $20 \mathrm{mg}$ with omeprazole $20 \mathrm{mg}$, it has been shown that esomeprazole $40 \mathrm{mg}$ is superior to omeprazole $20 \mathrm{mg}$ in GERD patients in whom endoscopy was performed to determine the rates of ulceration. ${ }^{10}$ Similarly, omeprazole $40 \mathrm{mg}$ was shown to be superior to omeprazole $20 \mathrm{mg}$ in healing gastric ulcer at 8 weeks $(83 \%$ versus $75 \%, P<0.05) .{ }^{12}$ So, while there appears to be a dose-response relationship,,$^{12}$ there appears to be no clinical evidence that the PPIs are not therapeutically interchangeable in the commercially available dose forms. Based on this information, many health care plans have considered PPIs relatively interchangeable, creating the opportunity to make OTC omeprazole the preferred drug when clinical, service, and cost outcomes are considered.

\section{Intervention Description}

This study evaluated the financial impact of an Arkansas State Employee Benefit Division (EBD) policy change on the health plan and its beneficiaries by examining the utilization and cost of PPIs during the 2 months prior to and following policy implementation. The EBD covers approximately 129,500 members with prescription benefits and had an annual drug budget of $\$ 74.6$ million in 2003. The EBD recently employed the help of a pharmacy benefits consultant (PBC), the University of Arkansas for Medical Sciences College of Pharmacy, to help make cost-effective, evidence-based decisions regarding the pharmacy formulary. One class of interest to the PBC was PPIs because they represented 12\% ( $\$ 8.9$ million) of the pharmaceutical costs for the EBD in 2003.

Under the preperiod formulary structure for PPIs, generic $\mathrm{Rx}$ omeprazole was covered in the first tier with a $\$ 10$ copayment; rabeprazole, esomeprazole, and Rx omeprazole were covered in the second tier with a $\$ 25$ copayment; and lansoprazole and pantoprazole were covered in the third tier with a $\$ 50$ copayment. The reimbursement provided to pharmacies by the EBD was the average wholesale price (AWP) minus $13 \%$ plus a $\$ 2.50$ dispensing fee for single-source brand products. The PBC recommended that OTC omeprazole become the preferred PPI. Upon receipt of the recommendation, the Drug Use Evaluation Committee for the EBD recommended changes to the beneficiary copayment as well as the pharmacy reimbursement structure to encourage use of OTC omeprazole. The EBD administrator adopted the policy recommendations. With the intent to provide a beneficiary incentive to switch from prescription-only PPIs to OTC omeprazole and to facilitate pharmacy participation, the benefit design was changed as outlined in Table 1 . The OTC-tier copayment became effective March 1, 2004, and the copayment change to the prescription PPI drugs became effective March 15, 2004. There was a 2-week lag time for the copayment change to allow for the policy decision to be communicated to all stakeholders.

The financial incentive to the beneficiary was significantthe new OTC tier had a $\$ 5$ copay per prescription. This relatively low cost share was made more favorable by the packaging of OTC omeprazole in 42 units (42 days supply). Since only 9 OTC omeprazole claims (of 42 units each) would be necessary per PPI utilizing member per year, there was an expected reduction of 3 prescriptions per year per beneficiary switched from a prescription PPI to OTC omeprazole. There was an appeal process for physicians, on behalf of a plan beneficiary, to request a prescription PPI at a lower copayment (\$25). A prescription PPI at a lower (\$25) copayment required 
verification of the diagnosis of Zollinger-Ellison (ZE) syndrome or other hypersecretory condition. The physician had to inform the EBD of the patient's condition and request approval for another PPI.

The purpose of the increased dispensing fee was to provide for pharmacy reimbursement that prevented a significant loss of pharmacy provider income that would otherwise be associated with converting a patient from a prescription PPI to OTC omeprazole. A sample of pharmacies in the pharmacy network were contacted to determine acquisition costs for all PPIs, including generic Rx omeprazole and OTC omeprazole. Using this information and the reimbursement formula in place at the time (AWP - 13\% + \$2.50), the gross margin for all prescription PPIs was estimated to be $\$ 13$ per claim. If OTC omeprazole was covered at the current reimbursement rate (i.e., AWP - 13\% + $\$ 2.50$ ), it was estimated that the gross margin would drop to approximately $\$ 3.50$. Thus, the $\$ 13$ dispensing fee was implemented to ensure that the new program (intervention) would be a relatively income-neutral decision per prescription for the pharmacy provider. With the $\$ 13$ dispensing fee, the gross margin for OTC omeprazole should be similar to the other PPIs. It was also suggested that the increased fee would help compensate pharmacists for the extra work in switching patients. The $\mathrm{PBC}$ and the Arkansas Pharmacists Association (APA) agreed that the higher (\$13) pharmacy dispensing fee would facilitate policy implementation while maintaining a positive relationship between the health plan and community pharmacies.

The EBD utilized direct communication with all stakeholders. A letter was sent to physicians and beneficiaries informing them of the new copayment tier designations for the specific PPIs with emphasis placed on the new $\$ 5$ copayment for OTC omeprazole. This communication also outlined the method that the decisions were made. In addition, the APA participated in the policy decision-making process and facilitated communication of the change to pharmacies, including endorsement of the increased dispensing fee. The APA communicated directly with district managers of chain pharmacies and pharmacy owners and provided educational materials to individual pharmacists across the state by using short fax messages as well as weekly reminders by e-mail messages prior to policy implementation. The information sent to pharmacies emphasized the $\$ 13$ dispensing fee that would be provided for each OTC omeprazole prescription dispensed. It is believed that the communication efforts of the EBD and the APA increased awareness of the formulary changes to all stakeholders.

\section{Evaluation of the Intervention}

The prescription claims database for the EBD was used to examine utilization and cost data for beneficiaries who received prescriptions for PPIs. Summary data included the number of prescriptions for each PPI and total ingredient cost, dispensing

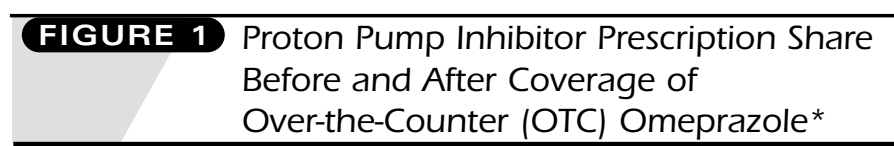

Before OTC Omeprazole Coverage

After OTC Omeprazole Coverage
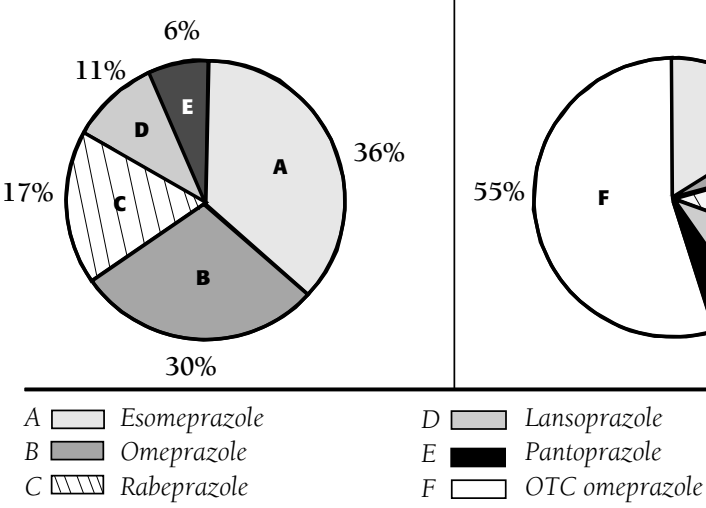

* Number of prescriptions before OTC omeprazole coverage (February 2004) = 6,700; Number of prescriptions after OTC omeprazole coverage (March and April 2004) $=14,295$.

fee, allowed charge, copayment, and amount paid by the EBD (net EBD cost). Data for claims with dates of service from January 1 to April 30, 2004, were extracted from the database, reflecting the 2 months prepolicy and postpolicy implementation. These data from 2004 were assessed to determine market share changes after policy implementation and the resulting shifts in ingredient costs, dispensing fees, amount paid by the plan, and amount paid by the beneficiary (copayment). Prescriptions per member per month (PMPM), days of therapy PMPM (days PMPM), charge PMPM, charge per prescription, charge per day, copay per prescription, net PMPM, and net cost per days of therapy were then calculated. Frequencies and derived measures are reported.

\section{Results}

From January 1, 2004, to April 30, 2004, 28,162 claims for PPIs were dispensed for beneficiaries of the Arkansas State EBD. Of these claims, $14,295(50.8 \%)$ were dispensed after the policy was implemented on March 1, 2004. A majority of PPI prescriptions were filled with OTC omeprazole after policy implementation. During the first week of the new policy (March 1 to 7 ), $47 \%$ of all PPI claims were for OTC omeprazole. OTC omeprazole represented $40 \%$ of all PPI claims in the second week and then remained steady at approximately $60 \%$ from the third week through the end of the study period. The proportion of total PPI prescriptions represented by OTC omeprazole was $54.8 \%$ in the first 2-month postperiod (following the change in drug coverage) compared with $0 \%$ in the 2-month preperiod (Figure 1). 


\begin{tabular}{|c|c|c|c|c|c|c|c|c|c|}
\hline & Members & Rxs & $\begin{array}{c}\text { Days } \\
\text { Supply }\end{array}$ & Days /Rx & $\begin{array}{c}\text { Ingredient } \\
\text { Cost }{ }^{\dagger}\end{array}$ & $\begin{array}{c}\text { Professional } \\
\text { FeeqI }\end{array}$ & $\begin{array}{l}\text { Allowed } \\
\text { Charge } \neq\end{array}$ & Copayment & $\begin{array}{c}\text { Net } \\
\text { EBD Cost§ }\end{array}$ \\
\hline $\begin{array}{l}\text { Preperiod } \\
\text { January } 2004 \\
\text { February } 2004 \\
\text { Total }\end{array}$ & $\begin{array}{l}128,646 \\
128,603 \\
257,249\end{array}$ & $\begin{array}{c}7,167 \\
6,700 \\
13,867\end{array}$ & $\begin{array}{l}217,377 \\
202,768 \\
420,145\end{array}$ & $\begin{array}{l}30.3 \\
30.3 \\
30.3\end{array}$ & $\begin{array}{c}\$ 879,325 \\
\$ 830,937 \\
\$ 1,710,262\end{array}$ & $\begin{array}{l}\$ 20,614 \\
\$ 19,262 \\
\$ 39,876\end{array}$ & $\begin{array}{c}\$ 899,939 \\
\$ 850,199 \\
\$ 1,750,138\end{array}$ & $\begin{array}{l}\$ 182,096 \\
\$ 172,046 \\
\$ 354,142\end{array}$ & $\begin{array}{c}\$ 718,682 \\
\$ 678,906 \\
\$ 1,397,588\end{array}$ \\
\hline $\begin{array}{l}\text { Postperiod } \\
\text { March } 2004 \\
\text { April } 2004 \\
\text { Total }\end{array}$ & $\begin{array}{l}128,872 \\
129,473 \\
258,345\end{array}$ & $\begin{array}{c}7,975 \\
6,320 \\
14,295\end{array}$ & $\begin{array}{l}273,852 \\
219,425 \\
493,277\end{array}$ & $\begin{array}{l}34.3 \\
34.7 \\
34.5\end{array}$ & $\begin{array}{c}\$ 612,891 \\
\$ 457,692 \\
\$ 1,070,582\end{array}$ & $\begin{array}{l}\$ 48,311 \\
\$ 41,261 \\
\$ 89,572\end{array}$ & $\begin{array}{c}\$ 661,202 \\
\$ 498,953 \\
\$ 1,160,155\end{array}$ & $\begin{array}{l}\$ 157,256 \\
\$ 147,720 \\
\$ 304,977\end{array}$ & $\begin{array}{l}\$ 504,807 \\
\$ 351,902 \\
\$ 856,709\end{array}$ \\
\hline $\begin{array}{l}\text { Change* } \\
\% \text { change }\end{array}$ & $\begin{array}{l}1,096 \\
0.4 \%\end{array}$ & $\begin{array}{c}428 \\
3.1 \%\end{array}$ & $\begin{array}{l}73,132 \\
17.4 \%\end{array}$ & $\begin{array}{c}4.2 \\
13.9 \%\end{array}$ & $\begin{array}{c}-\$ 639,680 \\
-37.4 \%\end{array}$ & $\begin{array}{l}\$ 49,696 \\
124.6 \%\end{array}$ & $\begin{array}{c}-\$ 589,983 \\
-33.7 \%\end{array}$ & $\begin{array}{c}-\$ 49,165 \\
-13.9 \%\end{array}$ & $\begin{array}{c}-\$ 540,879 \\
-38.7 \%\end{array}$ \\
\hline $\begin{array}{c}\text { Derived } \\
\text { Measures }\end{array}$ & $\begin{array}{c}\text { Rxs } \\
\text { PMPM }\end{array}$ & $\begin{array}{c}\text { Days } \\
\text { PMPM }\end{array}$ & $\begin{array}{l}\text { Charge } \\
\text { PMPM }\end{array}$ & Charge/Rx & Charge/Day & Copay /Rx & Net PMPM & $\mathrm{Net} / \mathrm{Rx}$ & Net/Day \\
\hline $\begin{array}{l}\text { Preperiod } \\
\text { January } 2004 \\
\text { February } 2004 \\
\text { Average }\end{array}$ & $\begin{array}{l}0.056 \\
0.052 \\
0.054\end{array}$ & $\begin{array}{l}1.69 \\
1.58 \\
1.63\end{array}$ & $\begin{array}{l}\$ 7.00 \\
\$ 6.61 \\
\$ 6.80\end{array}$ & $\begin{array}{l}\$ 125.57 \\
\$ 126.90 \\
\$ 126.21\end{array}$ & $\begin{array}{l}\$ 4.14 \\
\$ 4.19 \\
\$ 4.17\end{array}$ & $\begin{array}{l}\$ 25.41 \\
\$ 25.68 \\
\$ 25.54\end{array}$ & $\begin{array}{l}\$ 5.59 \\
\$ 5.28 \\
\$ 5.43\end{array}$ & $\begin{array}{l}\$ 100.28 \\
\$ 101.33 \\
\$ 100.79\end{array}$ & $\begin{array}{l}\$ 3.31 \\
\$ 3.35 \\
\$ 3.33\end{array}$ \\
\hline $\begin{array}{l}\text { Postperiod } \\
\text { March } 2004 \\
\text { April } 2004 \\
\text { Average }\end{array}$ & $\begin{array}{l}0.062 \\
0.049 \\
0.055\end{array}$ & $\begin{array}{l}2.12 \\
1.69 \\
1.91\end{array}$ & $\begin{array}{l}\$ 5.13 \\
\$ 3.85 \\
\$ 4.49\end{array}$ & $\begin{array}{l}\$ 82.91 \\
\$ 78.95 \\
\$ 81.16\end{array}$ & $\begin{array}{l}\$ 2.41 \\
\$ 2.27 \\
\$ 2.35\end{array}$ & $\begin{array}{l}\$ 19.72 \\
\$ 23.37 \\
\$ 21.33\end{array}$ & $\begin{array}{l}\$ 3.92 \\
\$ 2.72 \\
\$ 3.32\end{array}$ & $\begin{array}{l}\$ 63.30 \\
\$ 55.68 \\
\$ 59.93\end{array}$ & $\begin{array}{l}\$ 1.84 \\
\$ 1.60 \\
\$ 1.74\end{array}$ \\
\hline $\begin{array}{l}\text { Change* } \\
\% \text { change }\end{array}$ & $\begin{array}{l}0.001 \\
1.9 \%\end{array}$ & $\begin{array}{c}0.28 \\
17.2 \%\end{array}$ & $\begin{array}{l}-\$ 2.31 \\
34.0 \%\end{array}$ & $\begin{array}{l}-\$ 45.05 \\
-35.7 \%\end{array}$ & $\begin{array}{l}-1.82 \\
-43.7 \%\end{array}$ & $\begin{array}{l}-\$ 4.20 \\
-16.5 \%\end{array}$ & $\begin{array}{c}-2.11 \\
-38.9 \%\end{array}$ & $\begin{array}{l}-40.86 \\
-40.5 \%\end{array}$ & $\begin{array}{l}-1.59 \\
-47.8 \%\end{array}$ \\
\hline
\end{tabular}

* P values could not be calculated for these summary data for the population of all Arkansas State Employee Benefit Division (EBD) beneficiaries.

$\dagger$ Drug ingredient cost is average wholesale price - $13 \%$.

$¥$ Allowed charge is the sum of the pharmacy professional fee plus the drug ingredient cost.

$\S$ Net Arkansas State EBD costs are slightly higher than the allowed charge minus copayment because the net EBD cost includes the administrative fee

paid to the pharmacy benefit manager for processing the pharmacy claims.

II Dispensing fee may be greater than set reimbursement rate of $\$ 2.50$ due to generic incentive programs that pay a higher dispensing fee in the state employee health plan.

$R x=$ prescription; $P M P M=$ per member per month .

The number of PPI claims for the 2 months following policy implementation increased by 428 (3.1\%) over the prior 2 -month period. The average days of therapy per prescription also increased by $13.9 \%$ (from an average of 30.3 days per PPI claim to 34.5 days per PPI claims in the postperiod), a predictable result since the OTC omeprazole commercial package contains 42 units, generally equivalent to 42 days supply per claim.

In the postperiod, the number of PPI claims PMPM increased by $2 \%$, and the days of PPI therapy PMPM increased by $17 \%$ (1.91 in the postperiod compared with 1.63 in the preperiod). Although utilization appeared to increase in the immediate 2-month postperiod, representing a predictable outcome, the shift in market share in the postperiod resulted in significant net cost savings to the EBD and to the beneficiary on average and in particular for OTC omeprazole prescription claims. These summary data are shown in Table 2.

The EBD saved $\$ 40.86$ (40.5\%) per PPI claim in the first
2 months after implementation of OTC omeprazole. Thus, the amount paid by the plan decreased by approximately $\$ 270,440$ per month when comparing the 2 months prior to and following the policy implementation. The net PMPM cost decreased by $\$ 2.11$ (38.9\%), and the net cost per day of therapy decreased by $\$ 1.59$ (47.8\%); the decrease in net cost per day was $\$ 1.75$ (\$3.35 versus \$1.60, 52.2\%) in April 2004 compared with February 2004. A conservative estimate of annual savings derived from coverage of OTC omeprazole is $\$ 3,278,904$ based on average eligible membership of 129,500 . However, the increased utilization of OTC omeprazole in the second month (April 2004) of the postperiod is expected to continue, producing a PMPM savings of $\$ 2.56$ ( $\$ 5.28$ net PMPM cost for PPI in February 2004 versus $\$ 2.72$ in April 2004) or annual savings of $\$ 3,978,240$. The average copayment per PPI claim decreased from $\$ 25.54$ (2 months prior) to $\$ 21.33$ (2 months postperiod) per claim when comparing prepolicy and postpolicy implementation, saving beneficiaries $\$ 4.20$ (16.5\%) per PPI claim. 
The EBD plan was able to reduce net costs for PPI drugs despite an increase in dispensing fee for OTC omeprazole. The average dispensing fee increased by $118 \%$ (from $\$ 2.88$ to $\$ 6.27$ ) per claim. Most of the savings to EBD can be attributed to the decrease in ingredient cost. The ingredient cost per claim decreased by $39.3 \%$ (from $\$ 123.33$ to $\$ 74.89$ ) after coverage of OTC omeprazole. Measured by charge per day (including member cost share and net EBD cost), the savings on PPI drugs was $43.7 \%, \$ 2.35$ per day in the postperiod compared with $\$ 4.17$ per day in the preperiod. Figure 2 illustrates the weekly trends observed in average ingredient cost, amount paid by the EBD, copayment, and dispensing fee per claim for the 4 weeks prior to and the 8 weeks following policy implementation.

Twenty-two letters from physicians were received during the study period requesting, on behalf of a beneficiary, authorization to receive a third-tier PPI at the $\$ 25$ (second-tier) copayment. All 22 of these requests were denied because none of the beneficiaries had a diagnosis of ZE or other hypersecretory condition. Additionally, there was a lack of evidence that OTC omeprazole had been tried by the beneficiaries. All physicians were sent a letter reminding them of equipotent dosing of PPIs for the various indications.

\section{Discussion}

We report the initial implementation of a change to the health plan policy to encourage therapeutic interchange of an equivalent OTC product for its prescription-only alternatives. The EBD sought out the expertise of a PBC to obtain recommendations for cost-effective, evidence-based drug formulary changes that would produce cost savings for the EBD as well as beneficiaries. The PBC proposed the formulary change to the PPI class recognizing that the PPIs accounted for $12 \%$ of the EBD total drug budget in 2003. The new policy utilized a significant incentive to the beneficiary $-\$ 5$ copay versus $\$ 50$ copay per prescription. In addition, the pharmacy dispensing fee was increased significantly for the OTC omeprazole product (to $\$ 13$ from $\$ 2.50$ ) to encourage pharmacist participation in the therapeutic interchange of OTC omeprazole for prescription PPIs. These results suggest that the policy saved money for the plan sponsor and beneficiaries, despite the increased dispensing fee and initial increase in utilization.

The first 2 months of postpolicy implementation resulted in an approximate $60 \%$ shift of the PPI claims to the OTC product and an increase of 4.2 days of PPI therapy per prescription (13.9\%). The larger increase in days supply PMPM (17.2\%) compared with the number of prescriptions $(1.9 \%)$ is attributable to the 42-unit package size of OTC omeprazole, compared with 30 days for other PPIs. In the 2-month postperiod, OTC omeprazole was dispensed $54.8 \%$ of the time a PPI was dispensed.

The number of prescriptions increased by $1,096(0.43 \%)$ or by 0.001 (1.85\%) PMPM. This small apparent increase in the number of prescriptions in the postperiod may or may not be

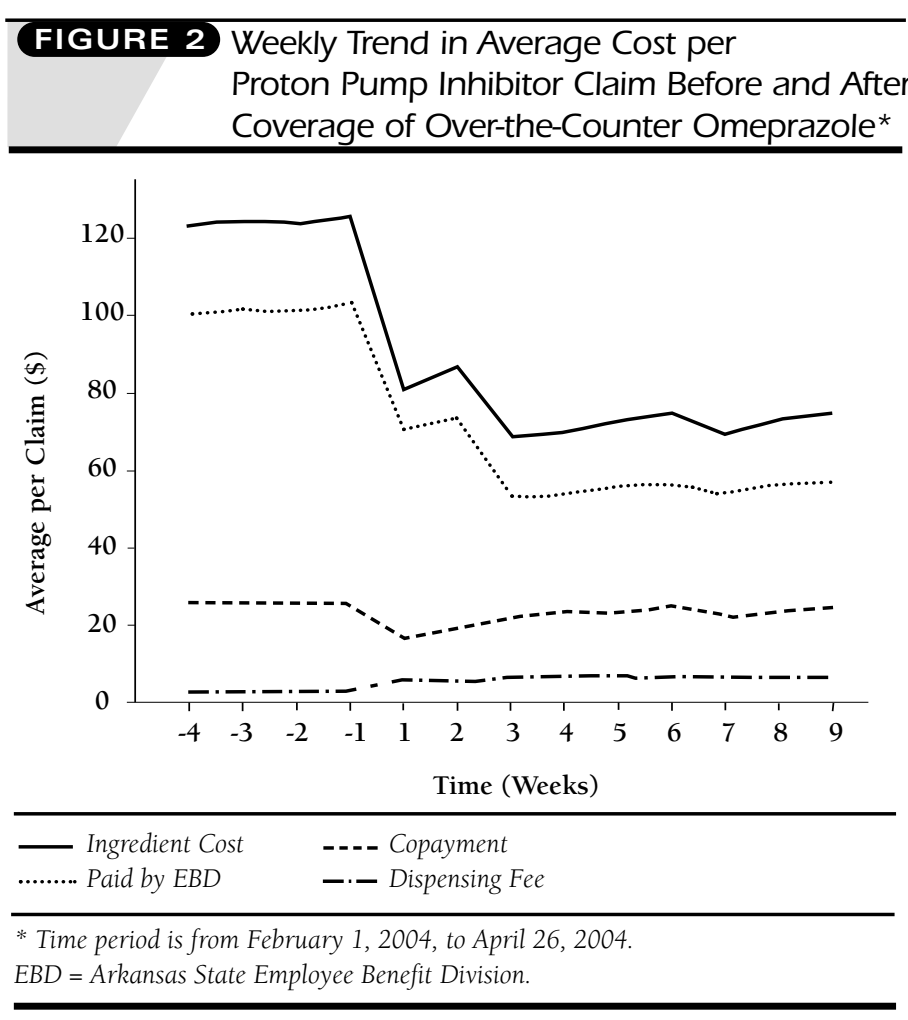

sustained. The small apparent increase may be associated with seasonal variation in PPI use or may be attributable to OTC coverage that permitted those beneficiaries who had previously purchased OTC omeprazole out-of-pocket to have the purchase subsidized by the EBD. OTC omeprazole had been on the market for several months prior to the policy implementation; thus, some beneficiaries may have been purchasing the OTC product out-of-their pocket. Further research will be necessary to determine the longer-term effects on the costs and utilization of PPI drugs in this health benefits plan.

The success of this policy change is attributed in large part to the financial incentives provided to beneficiaries and pharmacists to use OTC omeprazole. The increased dispensing fee was designed to make sure that pharmacists did not have an obvious, significant economic interest in dispensing a prescription PPI instead of OTC omeprazole. It also provided an incentive for the pharmacist to take the time to call the provider and request a change to the appropriate dose of OTC omeprazole and to explain the rationale for the change to OTC omeprazole to the beneficiary. Based on these results, it appears that pharmacists can facilitate a shift in prescription share. We could not, however, determine the relative effect of pharmacy reimbursement versus the beneficiary financial incentive on the favorable financial outcomes that we measured.

In making the formulary decision, it was important to 


\section{Effects on the Cost and Utilization of Proton Pump Inhibitors From Adding Over-the Counter Omeprazole to Drug Benefit Coverage in a State Employee Health Plan}

provide a financial incentive for the beneficiary to change PPIs, resulting in the new OTC copayment tier. The $60 \%$ of beneficiaries who shifted to OTC omeprazole experienced a significant decrease in copayment. However, almost half of the $40 \%$ of beneficiaries who remained on prescription PPIs experienced an increase in copayment from $\$ 25$ to $\$ 50$. Therefore, it would be expected that the average copayment would decrease over time as a greater percentage of beneficiaries switch to OTC omeprazole (i.e., $\$ 50$ to $\$ 5$ copayment per claim).

Nair and colleagues (2003) recently evaluated the impact of a 3-tier copayment pharmacy benefit structure on medication utilization behavior. Chronic disease sufferers from a health plan were switched from a 2-tier structure to a 3-tier structure. After the change, individuals with GERD were found to be the least formulary compliant. These results suggested that individuals with GERD are reluctant to change medications when their symptoms are controlled despite opportunities for decreased out-of-pocket costs. ${ }^{13}$ Many of the GERD patients continued to obtain third-tier drug products instead of switching to a first- or second-tier product. Alternatively, the results of this evaluation would suggest that some patients will switch PPIs when there is a financial incentive. The patient had a choice of a $\$ 5$ copayment for a 42-day supply of OTC omeprazole or a $\$ 50$ copayment for a 30-day supply of a prescription PPI, creating a significant economic incentive to switch to OTC omeprazole. The change in market-share percentages for each product provides further evidence that the copayment difference was an important factor in switching. Market share for the products initially on secondtier decreased significantly after the policy implementation. More of the beneficiaries who had a $\$ 10$ or $\$ 25$ copayment initially elected to try OTC omeprazole at a $\$ 5$ copayment. Market share for the third-tier products did not decrease as much, suggesting that a larger proportion of these beneficiaries chose to continue to pay the $\$ 50$ copayment.

Drug formulary cost savings were realized by the EBD's decision to pay for an OTC product with a $\$ 5$ copayment while increasing pharmacy reimbursement. The policy was designed so that it did not cause financial harm to the pharmacy while benefiting plan members and the health plan. This demonstrates the need for third-party payers to be flexible and consider all options when attempting to control drug costs. The decision to pay for an OTC product was based on the recommendation that the drug was clinically interchangeable with prescription products. When multiple generic PPIs become available at significantly lower costs, then perhaps different decisions will be made.

With today's prescription drug budget growing at double digits ${ }^{1-3}$ third-party payers should continuously evaluate their formularies and consider strategies to achieve cost savings when there is no significant clinical difference among drug products. In this case, the large difference in drug acquisition cost between OTC omeprazole and the other PPIs made it possible to implement a program intervention that provided financial benefit to pharmacists, drug plan members, and the drug plan sponsor. This policy decision saved the health plan approximately $\$ 67,000$ per week in the first 2 months following initiation, with PMPM savings growing in the latter part of the postintervention study period.

\section{Limitations}

We assessed only 2 months of prescription claims data before and after implementation of a change in prescription benefits. We believe that these data provide a conservative (underestimate) of savings to the state and to beneficiaries since the proportion of OTC omeprazole among total PPI utilization is expected to increase beyond the $54.8 \%$ observed in the first 2 months of the postperiod. However, longer-term evaluation will be necessary to determine if the pattern of change that we observed endures over time. This was a cost-outcome analysis, and we did not assess humanistic outcomes (e.g., either beneficiary or pharmacist satisfaction with the program) or clinical outcomes.

\section{Conclusion}

Health plans should consider coverage of OTC medications as a strategy to reduce pharmacy benefit costs. A change in policy to include coverage of OTC omeprazole reduced the net costs of PPIs for one state employee health plan by \$2.11 PMPM (38.9\%) in 2004 dollars in the first 60 days of implementation, after subtraction of increased pharmacy reimbursement and lower beneficiary copayments for OTC omeprazole and despite an increase in the average days supply per PPI prescription claim. Annualized savings to the state based upon the second month of experience were estimated to be $\$ 3,978,240$. An education program that informed physicians, pharmacists, and beneficiaries helped ensure that this policy change was successful and resulted in reduced costs for the health plan sponsor and its beneficiaries.

\section{ACKNOWLEDGMENTS}

The authors want to thank Cheryl Mokry, PharmD, Caremark, Nashville, TN, for providing data reports.

\section{DISCLOSURES}

No outside funding supported this study. Authors Brittany N. Harris, Donna S. West, Jill Johnson, Song Hee Hong, and Cindy D. Stowe disclose no potential bias or conflict of interest relating to this article. Harris served as principal author of the study. Study concept and design were contributed primarily by Harris, Johnson, and Stowe. Analysis and interpretation of data were contributed by Harris, West, Stowe, and Hong. Drafting of the manuscript was the work of Harris, West, Johnson, and Hong, and its critical revision was the work of Stowe. Statistical expertise was contributed by Hong and Caremark, Nashville, TN, and administrative, technical, and/or material support was provided by Caremark. 


\section{REFERENCES}

1. National Institutes for Health Care Management Research and Education Foundation. Prescription drug expenditures in 2001: another year of rising costs. Available at: www.nihcm.org. Accessed June 2, 2004.

2. Segedin DA. Three-tier copayment plans: design considerations and effectiveness. Drug Benefits Trends. 1999;11(9):43-52.

3. Penna P. Three-tier copayment systems and consumer concentric care. J Manag Care Pharm. 2000;6(5):351-54.

4. Harrington P, Shepherd MD. Analysis of the movement of prescription drugs to over-the-counter status. J Manag Care Pharm. 2002;8(6):499-508.

5. Aventis Pharmaceuticals Managed Care Digest Series. HMO-PPO/MedicareMedicaid Digest. 2003. Available at http://www.managedcaredigest.com. Accessed August 17, 2004.

6. Reynolds T. Switching from prescription to over the counter. Ann Intern Med. 2002;136(2):177-80.

7. Prilosec OTC Review. Two advisory committee members weigh in without voting. Pink Sheet. July 1, 2002.
8. Curtiss FR. New generic and OTC drugs provide opportunities for drug benefit managers. J Manag Care Pharm. 2002;8(6):520-21.

9. Klok RM, Pstma MJ, Van Hout BA, Brouwers JRBJ. Meta-analysis: comparing the efficacy of proton pump inhibitors in short-term use. Aliment Pharmacol Ther. 2003;17:1237-45.

10. Vakil N, Fennerty MB. Systematic review: direct comparative trials of the efficacy of proton pump inhibitors in the management of gastro-oesophageal reflux disease and peptic ulcer disease. Aliment Pharmacol Ther. 2003;18:559-68.

11. Bergara M, Vallve M, Gisbert JP, Calvet X. Meta-analysis: comparative efficacy of different proton-pump inhibitors in triple therapy for Helicobacter pylori eradication. Aliment Pharmacol Ther. 2003;18:647-54.

12. Valenzuela JE, Kogut DG, McCullough AJ, et al. Comparison of once-daily doses of omeprazole $(40 \mathrm{mg}$ and $20 \mathrm{mg}$ ) and placebo in the treatment of benign gastric ulcer: a multicenter, randomized, double-blind study. Am J Gastroenterol. 1996;91:2516-22.

13. Nair KV, Wolfe P, Valuck RJ, McCollum MM, Ganther JM, Lewis SJ. Effects of a 3-tier pharmacy benefit design on the prescription purchasing behavior of individuals with chronic disease. J Manag Care Pharm. 2003;9(2):123-33. 